Journal of Economics and Behavioral Studies

Vol. 4, No. 8, pp. 431-435, Aug 2012 (ISSN: 2220-6140)

\title{
Materialization of Behavioral Finance and Behavioral Portfolio Theory: A Brief Review
}

\author{
*Saqib Muneer, Saif-ur-Rehman \\ Faculty of Management and Human Resource Development (FPPSM) \\ University Technology Malaysia, Malaysia \\ *saqibmuneer85@gmail.com
}

\begin{abstract}
This study introduces the emergence of behavioral finance (BF) and behavioral portfolio theory (BPT). BF research dives the conventional suppositions of projected value optimization with coherent investors in proficient enjoinments. There are two major component of BF which are "way of people's thinking" (cognitive approach) and "when markets will be incompetent" (arbitrage limits). Behavioral portfolio theory describes investor's behavior, how they divide their wealth into portfolio mental account's layers (MAL) parallel of their ambitions. The development of BF study has stimulated due to the incapability of conventional structure to explore several pragmatic models.
\end{abstract}

Keywords: Behavioral finance; behavioral finance theory; arbitrage; Cognitive

\section{Introduction}

Every investor has some objectives regarding investment but primary objective of almost every investment is to make wealth. In the past, investor focused on performance, forecasting, market timing and some other factors before making investment. These factors based investments generated average outcomes, which mean investors are gain average wealth, and not much satisfaction for their intellect. In addition, in real there is a huge gap between profit gain and estimated profit. After these situation investors wants to find out actual reason behind this short actual received profit. They found the reasons behind this gap are crucial mistakes in the decision making process, after exploratory procedure. Simply we can say that due to less focus on the actual outcomes of the investment they were not able to make profitable investment decisions. In identifying these kinds of mistakes and ways to stay away, make excellence investment-decisions and outcomes, in investment decisions they recognized the blow of psychology. In this decade, research on BF began and researchers focusing in the field of $\mathrm{BF}$ and realizing the psychological process motivating such oversights. It means that, for researcher BF not a new theme in the field of finance and over the world it is accepted in markets like stock exchange market. In long run investment-decisions, several investors consider that psychology play a very important role in describing the behavior of these markets. However, in the recent times a set of intensive proper studies have been undertaken in this vicinity. Misperceptions of individual regarding risk was documented by Slovic (1972) and Tversky \& Kahneman $(1974,1979)$ worked on heuristic driven decision biases and frames of decision frames, contributions of these studies played a vital role in BF. The outcome of such studies was at divergence by means of the coherent, egocentric decision-maker posited by economics theory and traditional finance.

Behavioral finance defines in several ways and there is substantial concurrence between these definitions. Every researcher defines behavioral finance in its own way for example; In Lintner (1998) point of BF is the study which explains how humans understand information and act on it to make conversant decisions. Olsen (1998) emphasizes that 'BF tries to recognized and forecast reasonable financial insinuation psychological decisions process, rational' behavior, unfair or imperfect are not describe in this. At the time, it can be noticed that no integrated theory of $\mathrm{BF}$ present. $\mathrm{BF}$ is the pattern where financial markets are considered using models that are less tapered than those based on Von-Neumann-Morgenstern (VNM) anticipated utility theory and arbitrage assumptions. Specifically, BF has two major components: one is cognitive psychology and the second is arbitrage's Limits. Cognitive approach to thinking of people and there is a huge literature on this psychology, which explains that in the way that people think they make systematic mistakes. Due to overconfidence, they emphasize on recent experience, forecasting ability, etc. They make their own choices and preferences of them can be generate misrepresentation. BF utilizes this information, instead of 
captivating the overconfident option that it can be overlooked. In what situation arbitrage services will not be effective, and at what time they effective, limits to arbitrage predict this information. BF considers such frameworks in which some negotiators are irrational, either because of erroneous beliefs or because of inclinations. If it is uncomplicated to take positions and over a short period, these misevaluations might be corrected, then arbitrageurs will take positions. They abolish these mispricing before they become huge. If these positions are not easily to take, due to constraints on short sales, or if there is no confirmation that within a reasonable timeframe the mispricing will be corrected, in this situation arbitrage will not able to correct the mispricing phenomena. Indeed, Arbitrageurs are always tried to avoid such markets where mispricing is prevail at high just because of high risk. A brief review of two major components of behavioral finance will provide better understanding of human behavior.

\section{Cognitive Biases}

Regarding how people behave, cognitive psychologists have described many patterns. Several patterns of cognitive biases are as follows:

Heuristics: This make decision-making easier, we can also called this "Rule of Thumb". However, when sometimes things change they can lead to biases and this can lead to suboptimal decisions regarding investment. Several investors assign with the $1 / \mathrm{N}$ rule in a situation where number $(\mathrm{N})$ of choices regarding invest their pension fund in which activities. If there are two three kinds of funds, two-third and one-third goes into each. Benartzi and Thaler (2001) explored $1 / \mathrm{N}$ rule is very popular among people, means that they follow this rule for the best use of their money.

Conservatism: Investors normally slow to notice the changes when things change gradually. In other words, they feel that they are secure so other things are also on the same mode. The conservatism favoritism is at conflict with the representativeness unfairness. If circumstances change, Investor might be not able to react because of the conservatism favoritism. However, then they can be adjust with these changes if there is a long enough pattern and may be underweighting, dramatize the long-term average.

Overconfidence: it means that investors mostly rely on their skills and capabilities to do work. Overconfident is such quality that especially related to entrepreneurs and this understandable itself in many traditions. For a case "too little diversification", it is because of a propensity to authorize a person according to his capabilities. Public firms are the focus of such kind of investors to invest money, although in diversification viewpoint this is bad to invest in these companies because their real estate is coupled with future of company. Barber and Odean (2001) analyzed in their research that the Investors are trading with brokers how discount brokerage accounts have and more investors did worse when they traded on the average. In addition, male investor did worse more than women did, when they traded more.

Framing: This means in which way a conception is present in individual's affairs. Lest take a case, restaurants may promote special offers and can be special discounts, but they never, use surcharges at boom time of business. By using special offers and discounts business growth at its increase because customers thought that they are receiving a discount at off-boom times instead of paying a surcharge at boom times, although same prices are coated. Cognitive psychologists explained that if doctors see confirmation which is offered as "mortality rates" Instead of "survival probabilities," they make different suggestions although mortality rates plus survival probability adds up to $100 \%$.

Psychological (Mental) Accounting: Occasionally investor makes different decisions in their minds but in principle, they should be united. Let us take an example; several investors make their plans about monthly expenses of house and budget concerning household food, budget for outing and entertainment budget. In the house, where the budget of food is present, they will not eat expensive things like burgers, Pizza because these are very classy than a chicken roast, which make at home. However, in a restaurant, they will order expensive food for dinner. They can save money if they ate and made classy foods in home and ate normal food in the restaurant. However, because of classifying restaurant food and homemade food in different category, they put some limits on the food that they made at home. 
Representativeness: People always focus on long-term averages instead of short term. People emphasize more on their recent experience rather than other factors. Sometimes it can be call as the law of small numbers or game of small numbers. For example, several investors begin to believe on high return on equity is common when for many years return on equity have been high.

\section{Arbitrage Limits (Limits to arbitrage)}

Underassessment of assets known as "Financial Assets" is frequent in practices, but it is not simple to make regularly profits off, of this underassessment and the question arise why this happen. Underassessment categories in two types: some are arbitrage-able or called recurrent and other are long-term in nature or nonrepeating. Intended for the recurrent underassessment, strategies of trading can consistently produced wealth. Because of this, hedge funds and others zero in on these. Keep them from ever getting too big and thus, the market is quite efficient for these assets, at least on a relative basis. For the long-term in nature and non-repeating underassessment, it is not possible in actual time to spot the vicissitudes until they have passed. Getting into too early risks losses, this can wipe out capital. If limited partners or other investors are not willing to supply funds, extractions of capital after a trailing streak, may actually result in buying or selling stress that aggravates the inefficiency, this is even a worse situation. Just who are the investors who will turn inefficient markets into efficient one? Well, one observable class of investors who are trying to make money by recognizing underassessment is hedge funds. Buying underrated securities, then exploring highly correlated securities that are overrated and shorting them; by doing this, a relative value hedge fund takes long and short positions. On the other hand, a macro hedge fund takes provisional positions that cannot be easily hedged, for example shorting NASDAQ takes provisional position during the last two years. How well do hard works by arbitrageurs to make profit work in perform at making markets more proficient. As Shleifer and Vishny (1997) documented in their article (Limits to Arbitrage), that the efforts of arbitrageurs to make money can be turn some markets into more efficient, but they have no any effect on other efficient or inefficient markets.

\section{Behavioral Portfolio Theory (BPT)}

In 1957 proto-behavioral period of finance was just started when a researcher Snyder (1957) trained to common investors "how to take a loss and like it" this is the name of his article. He wrote, "There is no loss without collateral compensation," and explained that by reducing taxes and realizing losses we can increases our wealth. He further explained that common investors are hesitant to realize the actual losses. We are not keen to take a toss until we are forced to do it this is he called "Human nature being what it is". Habitually, by not realizing or ignoring a loss it is believe that, we will someday put a glimpse on financial asset for finding of losses, after shown quite admiration and also recovered its original value. Shefrin and Statman (1985) reintroduced the Snyder's examination about the disinclination of common investors to realize losses more that was a more than a half a century ago, as the "disposition effect", the premature period of BF. Protobehavioral finance (PBF) was the stout period of finance. It explored common human behavior, included various human distresses, and renowned several human proclivities, but it was amorphous and flabby, often going straight from anecdote to speculation and to broad conclusion. Shefrin and Statman (2000) introduced BPT and this is a goal-based theory. The theory explained that how investors segregate their money into several MAL. They divide money in account layers of a portfolio pyramid according to their goals like retirement plans, education of children, being rich enough, or make entertainment plans to hop on a journey ship whenever they please. Friedman and Savage (1948) started the BPT more than 60 years ago, he noted that hope for riches and shelter from poverty share roles in our behavior. Some people buy lottery tickets and as well as they buy insurance policies. It means that people are risk-seeking that's why they buy lottery tickets and on the other hand they are also risk-averse that's why they buy insurance policies as well. After few years, Markowitz (1952a, 1952b) worked on behavior of human and explained two quite sprats' points of behavior. Markowitz (1952a) formed a mean-variance theory: expected utility theory was the base of his theory. On the same time, Markowitz (1952b) comprehensively explained the Friedman and Savage's framework of insurance-lottery. Investors in theory of mean-variance always risk averse not risk seeker, not like investors in the framework of insurance-lottery. 
Friedman and Savage (1948) explained that people want to approach in higher a societal class that is why they buy lottery tickets; on the other hand, they buy insurance which protect them against falling into lower social classes. Markowitz (1952b) further cleared picture of examination of Friedman and Savage after writing that people always attempt to shift out from their present position to higher position or classes. Therefore, people of lower classes with 100 dollar may admit lottery-like chances in the anticipation of captivating 1 million dollar, and with 1 million may admit lottery-like chances in the expectation of captivating 100 million dollar. The work of Markowitz (1952b) extended by Kahneman and Tversky (1979) into prospect theory. It explains the people's behavior who admits a lottery ticket probability when their ambition is higher than their current level but they discard this probability when ambitions are below their levels. An essential aspect in BPT is the examination that people as a whole not consider their own portfolios, as described by portfolio theory of mean-variance. Although, consider as separate MAL in a pyramid of assets, where these layers are linked by specific objectives and their approach regarding risk differ crossways layers. MAL can be a downside protection layer (DPL) and upside potential layer (UPL). DPL provide a safeguard to investors from losing their current position or wealth and UPL provide opportunity to investors for being rich. Investors can be acting as if they disgust risk in the DPL, on the other hand they act as if they love risk in the UPL. Investors, which are dynamic by ambitions not by attitudes toward risk, are called customary proverbial investors. Das, Markowitz, Scheid \& Statman (2010) introduced a new theory of mental accounting portfolio by combining theory of mean-variance portfolio and theory of behavioral portfolio. Investors start to distribute their money according objectives into MAL, for example, $65 \%$ to pension fund, $20 \%$ to university means, and $15 \%$ hop of a journey trip after become rich at whatever time they feel happy. In the next, investors identify the preferred prospect of reaching the doorstep of each objective, for example, $90 \%$ for pension fund, $55 \%$ for university means, and $30 \%$ for getting wealthy. In the light of mean-variance theory, each MAL is now optimizing as a sub- portfolio and each realistic objective is accomplishing with a combination of assets. By considering the above example, the pension objective is expected to be achieved in a sub-portfolio with an incarnation biased in the direction of bonds. The university objective is probable to be achieving in a sub-portfolio with an impartial permutation of stocks and bonds. Third objective to become wealth is possible to be achieving in a sub-portfolio with a permutation weighted toward stocks, maybe with some options and lottery-tickets terrified in. Taken, as a whole portfolio is the computation of the mental account sub-portfolios and it, resembling the sub-portfolios, under the mean-variance efficient boundary.

\section{Conclusion}

This succinct introduction to behavioral finance and behavioral portfolio theory has only discussed a few aspects. This is quite difficult to search out some strategies of trading which constantly produced wealth for investors. It does not entail that financial markets are information-ally proficient, on the other hand. Squat incidence under-assessments can be huge, lacking of giving some prospect to constantly construct wealth. In the process of decision-making, behavioral factors play a very vital role for the investors. It is the age that endeavors for a brawny and fit finance. It comprises investigations into why Investor deal and devour more from dividend than capital. How people become socially responsible and want to invest in socially responsible organizations or impatient to invest in hedge finances. Fairly speaking BF is in its formative years. It is not a split directive, although as an alternative will gradually be fraction of conventional finance.

\section{References}

Barber, B. \& Odean, T. (2001). Boys will be boys: Gender, overconfidence, and common stock investment. Quarterly Journal of Economics, 116, 261-292.

Benartzi, S. \& Thaler, R. (2001). Naïve diversification strategies in defined contribution savings plans. American Economic Review, 91, 79-98.

Das, S., Markowitz, H., Scheid, J. \& Statman, M. (2010). Portfolio Optimization with Mental Accounts. Journal of Financial and Quantitative Analysis, 45(2), 311-334.

Friedman, M. \& Savage, L. (1948). The Utility Analysis of Choices Involving Risk. Journal of Political Economy, $56(4), 279-304$.

Kahneman, D. \& Tversky, A. (1979). Prospect theory: An analysis of decision making under risk. Econometrica, 47(2), 263-291.

Lintner, G. (1998). Behavioral finance: Why investors make bad decisions. The Planner, 13(1), 7-8. 
Markowitz, H. M. (1952a). Portfolio Selection. Journal of Finance, 7(1), 77-91.

Markowitz, H. M. (1952b). The Utility of Wealth. Journal of Political Economy, 60(2), 151-158.

Olsen, R. (1998). Behavioral finance and its implications for stock price volatility. Financial Analysts Journal, 54(2), 10-18.

Shefrin, H. M. \& Statman, M. (1985). The Disposition to Sell Winners Too Early and Ride Losers Too Long: Theory and Evidence. Journal of Finance, 40(3), 777-790.

Shefrin, H. M. \& Statman, M. (2000). Behavioral Portfolio Theory. Journal of Financial and Quantitative Analysis, 35(2), 27-151.

Shleifer, A. \& Vishny, R. (1997). The limits of arbitrage. Journal of Finance, 52, 35-55.

Slovic, P. (1972). Psychological study of human judgment: Implications for investment decision making. Journal of Finance, 27, 779-801.

Snyder, W. H. T. (1957). How to Take a Loss and Like It. Financial Analysts Journal, 13(2), 115-116.

Tversky, A. \& Kahneman, D. (1974). Judgment under uncertainty: Heuristics and biases. Science, 185, 11241131. 